\title{
РАЗВИТИЕ СУДОСТРОИТЕЛЬНОЙ ПРОМЫШЛЕННОСТИ В КОНТЕКСТЕ НЕОИНДУСТРИАЛИЗАЦИИ "
}

\section{(c) 2021 Шарафутдинова Лилия Ражаповна}

аспирант кафедры экономики и управления предприятиями и производственными комплексами Санкт-Петербургский государственный экономический университет, Россия, Санкт-Петербург

E-mail: liliya.sharafutdinova22@gmail.com

Работа посвящена вопросу развития судостроительной промышленности в контексте неоиндустриализации. Определены возможности управления цепочкой создания ценности в условиях цифровизации производства. Предложены пути расширения сетевого взаимодействия предприятий судостроительной и смежных отраслей промышленности в условиях цифровой индустриализации.

Ключевые слова: неоннустриализация, судостроительная отрасль, высокотехнологичное предприятие, цифровые технологии

Модернизация мировой и отечественной промышленности на пути инновационного развития неразрывно связана с этапом неоиндустриализации. Нужно отметить, что само понятие неоиндустриализации трактуется неоднозначно различными авторами. Так, например, С.А.Толкачев определяет неоиндустриализацию как «процесс широкомасштабного внедрения комплекса прорывных технологий обрабатывающей промышленности, в результате чего: происходит частичное изменение парадигмы производственной деятельности (аддитивное производство вместо субтрактивного); интегрированное непрерывное электронное управление расширенным производственным циклом продукции (промышленный интернет или технотронное общество), позволяющее переходить к киберфизическому типу производства; новый этап роботизации производства, позволяющий органически сочетать труд машины и человека» [16]. С.С.Губанов трактует этот термин как «исторически закономерный процесс развития производительных сил, который разворачивается после завершения в основном первой фазы индустриализации - электрификации. Он представляет собой вторую фазу индустриализации, т.е. автоматизацию и компьютеризацию производственного аппарата». Свои определения дает С.Д. Бодрунов [17,18], однако все авторы сходятся в том, что неоиндустриализация есть воссоздание отечественной промышленности на новой технологической основе.

Одним из приоритетных стратегических направлений промышленности является развитие

судостроительной отрасли. Судостроительная отрасль в своей основе содержит высокие, наукоемкие технологии, используемые при производстве судов, а также для обеспечения стойкой инновационной инфраструктуры. Согласно исследованию судостроительной промышленности России на 2020-2021 гг. запланировано производство 350 судов и кораблей, что может говорить о сравнительно низкой загруженности производственных мощностей отечественных верфей [15]. Преимущества цифровых возможностей и передовых технологий позволяют существенно оптимизировать производственные процессы, и, в свою очередь, решение вопросов, связанных с переходом к цифровизации производства отрасли, способствует реализации долгосрочных планов её развития, повышению спроса на продукцию различных сегментов судостроения, «преодолению цифрового разрыва», что обуславливает актуальность и научную значимость проблемы.

Развитие судостроительной промышленности регламентируется различными стратегическими документами, например, в «Стратегии развития судостроительной промышленности на период до 2035 года» [3], «Морской доктрине Российской Федерации» [2], указе Президента Российской Федерации от 20 июля 2017 г. № 327 «Об утверждении Основ государственной политики Российской Федерации в области военноморской деятельности на период до 2030 года» [5], «Стратегии развития морской деятельности Российской Федерации до 2030 года» [4] и др.

Судостроительная отрасль включает воен-

\footnotetext{
* Исследование выполнено при финансовой поддержке РФФИ и БРФФИ в рамках научного проекта № 20-51000002.
} 
ное и гражданское судостроение, морское и речное. Ряд таких особенностей, как длительность цикла строительства, высокая капиталоемкость продукции, научно-технический потенциал, уникальность каждого продукта, импортозависимость и др. требуют значительных усилий для повышения конкурентоспособности отрасли и достижения целей развития. В настоящее время лидерами рынка судостроения являются Южная Корея, Китай и Япония. Согласно отчету ООН в 2020 году наибольшее количество судов произведено в Китае (5 206 шт.), востребованность которых также подтверждена количеством заказов [14].

В первой половине 2020 года объем мирового судостроения составил 269 судов/5,75 млн. CGT (рисунок 1).

Основными секторами роста в 2020 году стали газовозы, нефтяные танкеры, затем балкеры и контейнеровозы. Производство судов Китаем составляет $61 \%$ от всех мировых заказов. Одна- ко, в целом, по сравнению с 2019 годом показатель глобального портфеля заказов снизился на 42\%. В третьем квартале 2020 года Россия заняла 3 место в мировом судостроении. Новая коронавирусная инфекция COVID-2019 оказала значительное влияние на строительство, поставку судов. В начале 2020 года зафиксирован рост мирового торгового флота на $4,1 \%$, однако, в июле 2020 года количество заказов, согласно исследованию Британского аналитического агентства, сократилось на $53 \%$, что также свидетельствует о неопределенности экономических последствий в будущем [9].

Наибольшую долю в мировом флоте - 56,7\% в совокупности составляют судостроение Греции, Японии, Китая, Сингапура, Гонконга, Германии, Республики Кореи. Доля мирового флота Российской Федерации занимает $1,13 \%$, комплекс проблем судостроительной отрасли России препятствует развитию технологических направлений, соответствию зарубежным аналогам.

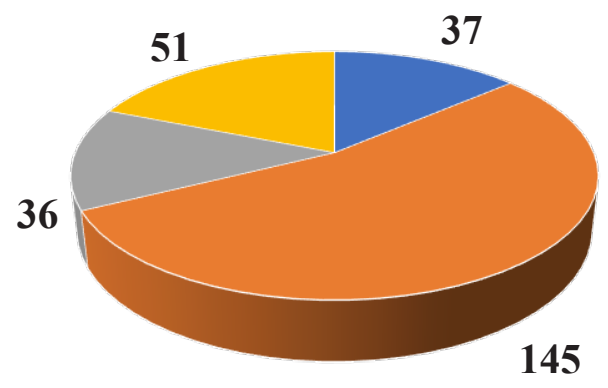

- Южная Корея - Китая - Япония - Другие страны

Рисунок 1. Мировой портфель заказов на строительство судов (первое полугодие 2020 года) [14]

Таблица 1. Показатели мирового судостроения по странам [14]

\begin{tabular}{|l|l|l|l|l|}
\hline \multicolumn{1}{|c|}{ Страна } & Количество судов & Общий дедвейт, т & $\begin{array}{l}\text { Иностранный флаг } \\
\text { в отебо дед- }\end{array}$ & $\begin{array}{c}\text { Доля страны в ми- } \\
\text { ровом флоте, \% }\end{array}$ \\
\hline Греция & 4648 & 363854232 & 83,28 & 17,77 \\
\hline Япония & 3910 & 233134877 & 84,21 & 11,38 \\
\hline Китай & 6869 & 228376872 & 56,44 & 11,15 \\
\hline Сингапур & 2861 & 137299726 & 45,55 & 6,70 \\
\hline Гонконг, Китай & 1690 & 100957393 & 28,18 & 4,93 \\
\hline Германия & 2504 & 89403077 & 90,67 & 4,37 \\
\hline Республика Корея & 1615 & 80582635 & 82,13 & 3,93 \\
\hline Норвегия & 2043 & 63935810 & 97,05 & 3,12 \\
\hline Бермудские острова & 542 & 60413871 & 99,46 & 2,95 \\
\hline США & 1930 & 57216830 & 82,11 & 2,79 \\
\hline Российская Федерация & 1742 & 23105563 & 64,11 & 1,13 \\
\hline Другие страны & 22607 & 609694561 & 61,85 & 29,78 \\
\hline Итого & 52961 & 2047975447 & 71,8 & 100,0 \\
\hline
\end{tabular}


Каждой стране присущ ведущий тип судостроения, например, в Китае главными направлениями являются строительство сухогрузов (56,2\%), морских судов (58\%), грузовых судов (34,6\%); в Республике Кореи - производство газовозов (62,8\%), нефтяных танкеров (59,4\%), контейнеровозов (41,7\%); в Японии - химические танкеров (54\%). В структуре российского судостроения $68 \%$ составляют танкеры, $16 \%$ суда для генгрузов.

По данным Минпромторга за 2019 год объём выпуска продукции судостроения сократился на 6\% по сравнению с 2018 г. Согласно статистическим данным строительство кораблей, судов и плавсредств водоизмещением более 100 т. воз- росло на 30\%, однако в 2019 году в количественном выражении отмечается сокращение как в гражданском, так и военном сегменте [10]. За период 2012-2018 гг. в России построено более 800 судов. В соответствии с отчетом Крыловского государственного научного центра приоритетом в задачах отечественного судостроения на среднесрочную перспективу является закрепление позиций в строительстве ледоколов и судов арктического плавания, фокус на расширении доли отечественных промысловых судов с последующим импортозамещением оборудования.

Автор рассмотрел факторы, способствующие и препятствующие развитию. Результаты представлены на рисунке 3.

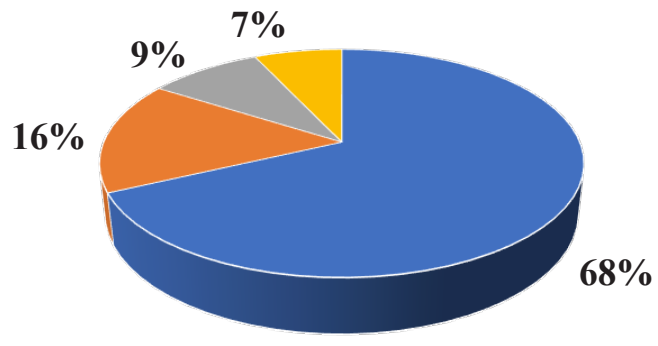

- Танкеры - Суда для генгрузов " Балкеры "Другие

Рисунок 2. Структура отечественного судостроения по классам судов,\%

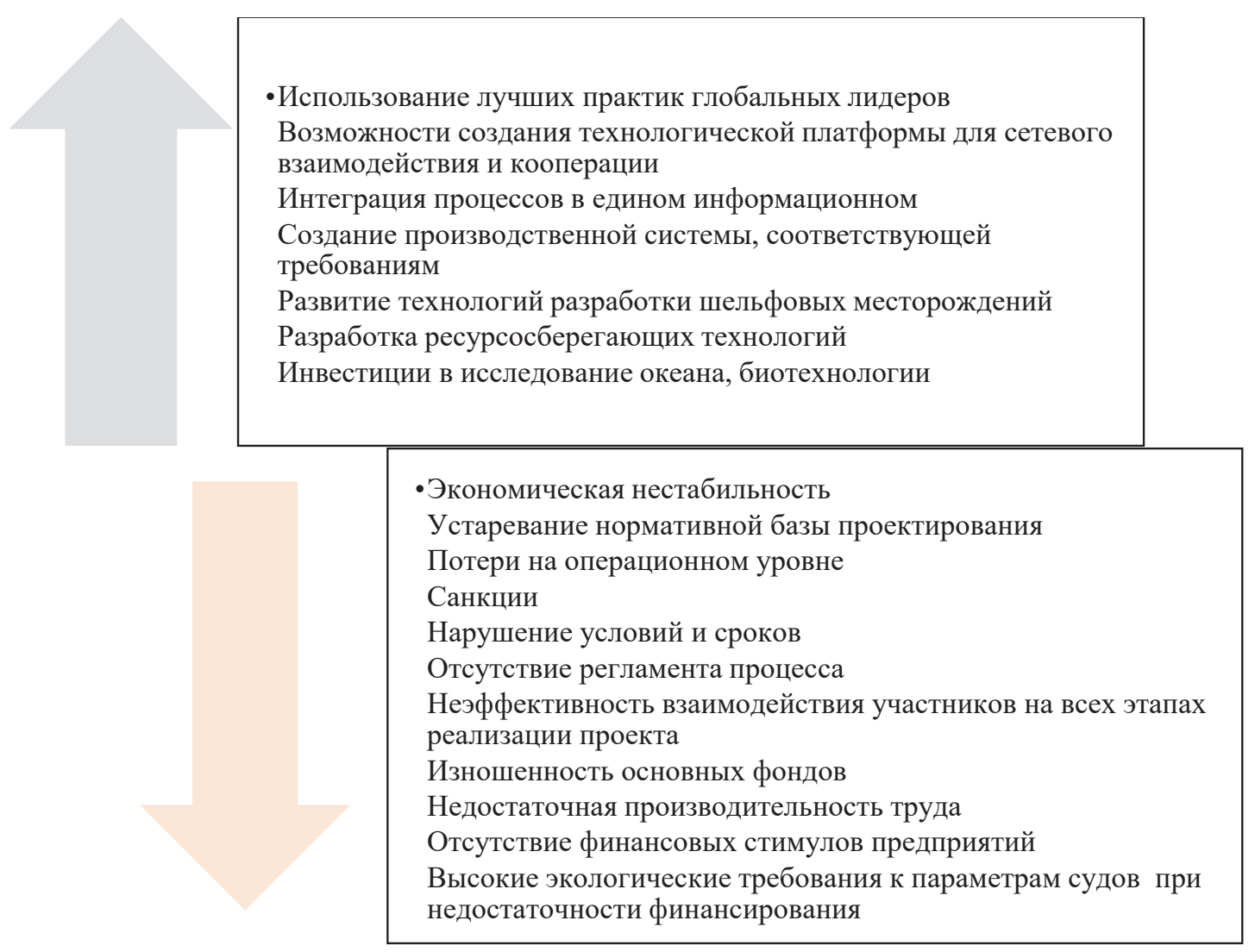

Рисунок 3. Факторы, способствующие и препятствующие развитию судостроения 
Одним из ключевых факторов развития является технологическое опережение при соответствующей инфраструктуре. Отметим, что отрасль судостроения, находящаяся в тесном взаимодействии со смежными отраслями промышленности, влияет на научно-технологический прогресс предприятий промышленности.

Наличие высоких технологий обусловило существование обязательных требований к составу, качеству и способам использования ресурсных компонентов, соблюдение которых выделяется среди высокотехнологичных предприятий. Их бизнес-модель основана на высоком уровне функционирования процессов, управления, стратегически значимых результатов. Развитие высокотехнологичных предприятий способствует созданию новых промышленных возможностей для развития отрасли судостроения и смежных отраслей. В связи с активным ростом арктического судостроения ожидается запрос со стороны зарубежных компаний на постройку научно-исследовательских судов, транспортных, судов технического флота и морской техники усиленного ледового класса, что подтверждает необходимость развития высокотехнологичных предприятий.

Таким образом, перспективными областями развития судостроения являются высокотехнологичные судостроительные предприятия, строительство судов крупноблочным способом; строительство судов и морской техники для освоения шельфовых месторождений, использование цифровых технологий, средств автоматизации, роботизации производств и др.

Как отмечает Губанов С.С., если процесс индустриализации завершается крупномашинным производством, то неоиндустриализация является второй цифровой фазой индустриализации, связанной с полной автоматизацией производительных сил [8].

В докладе о Морской политике России в 2019 году обозначены элементы технологического направления развития цифровизации судостроительных предприятий:

- необслуживаемые киберфизические устройства - коммутационные устройства, преобразователи, для производства продукции;

- цифровые системы микросети, энергетическая инфраструктура зданий и сооружений;

- интеллектуальные системы диагностики оборудования;

- распределённая автоматизация объектов энергетики и др. [11].

Особенностями процесса неоиндустриализации является функционирование базисного продукта - единой системы машин вместо отдельных коопераций. В свою очередь, управление жизненным циклом судов является одним из важнейших аспектов эффективного судостроения. Если неоиндустриализация как объективная тенденция развития мировой экономики оказывает значительное влияние на все рынки, также и цифровые технологии становятся одним из факторов, сопровождающих все этапы жизненного цикла судна. Эксперты отмечают, что внедрение цифровых технологий позволит снизить себестоимость до $30 \%$.

Экономическая составляющая постройки судов зависит и от цены, и от себестоимости постройки. Факторы, влияющие на себестоимость, включают материалы, трудовые затраты, расходы верфи, проектирование, период постройки, требования судовладельца, стоимость финансирования и страхования постройки, стоимость банковской гарантии на авансовые платежи, что можно разгруппировать на затраты, обеспечивающие работу; работу, формирующую ценность для заказчика и работу, не добавляющую ценность продукту.

Схема, показанная на рис. 4, представляет собой структуру основных затрат в соответствии со стадиями жизненного цикла судна. Стоит отметить, что в ходе производства судна помимо косвенных и прямых расходов существует ряд потерь, которые являются избыточными и влекут за собой перерасход ресурсов, увеличение себестоимости судна, снижение рентабельности производства.

Для достижения целевой себестоимости необходим контроль факторов, оказывающих влияние на эту величину, ресурсы предприятия. Формирование соответствующей базы знаний о процессе, ресурсах, задействованных при постройке судна позволило бы своевременно выявить потери и принять меры по их минимизации и ликвидации. Цифровые технологии за счёт своих преимуществ могут способствовать оптимальному снижению себестоимости.

В целях решения задачи повышения эффективности производственного процесса промышленные предприятия различных отраслей применяют большое число инструментов и методик. Например, японская модель управления Lean Production - концепция бережливого про- 


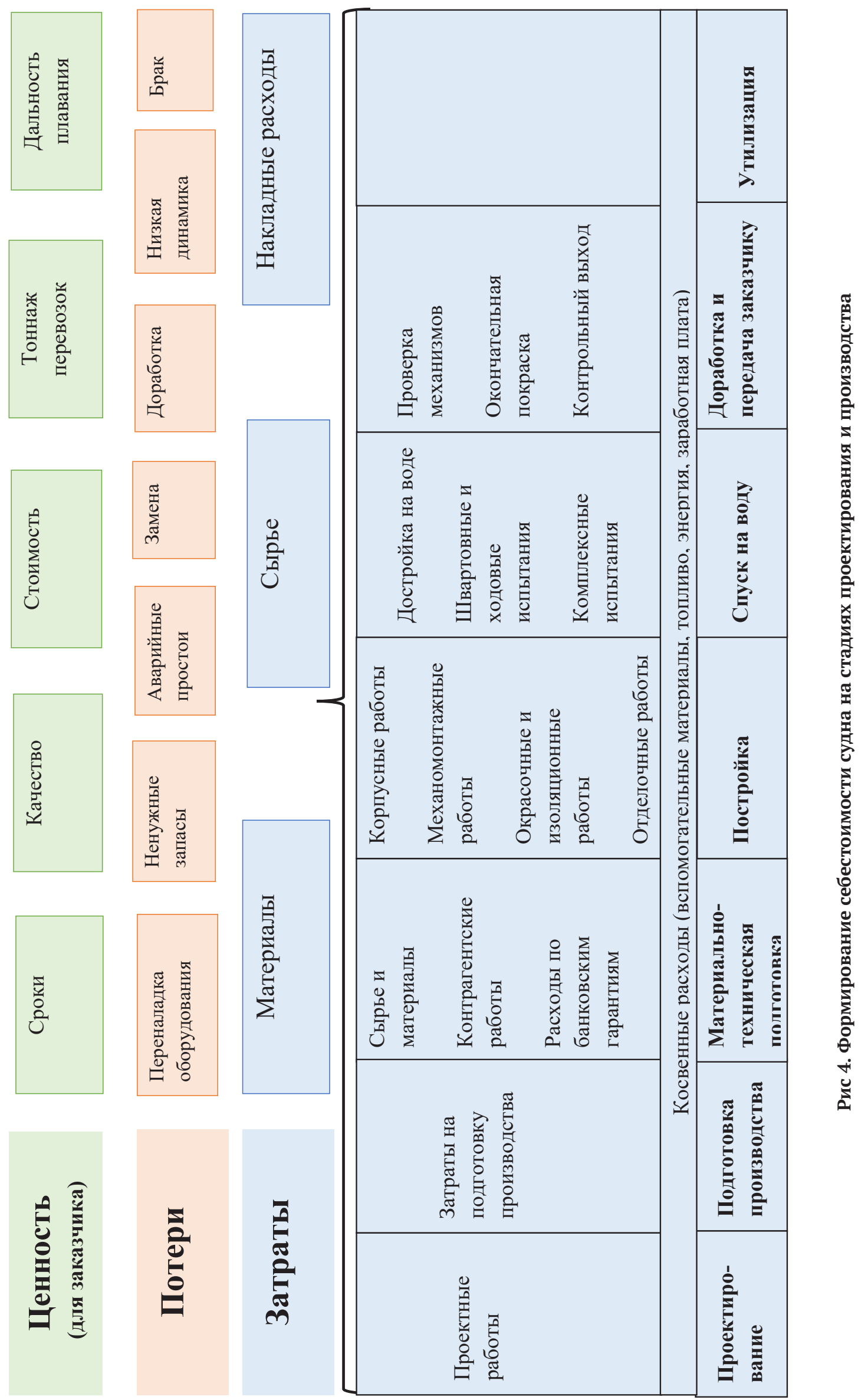


изводства, впервые была внедрена в автомобилестроении в компании Toyota. Она предполагает оценку ценности продукта на каждом этапе его создания с выявлением потерь, которые не добавляют ценность продукту. Создателем производственный системы компании Toyota Тайити Оно выявлено 7 видов потерь: потери из-за перепроизводства, потеря времени из-за ожидания, потери из-за лишних запасов, потери из-за лишних этапов обработки, потери из-за выпуска дефектной продукции, потери при ненужной транспортировке. Задачей «бережливого производства» является снижение, ликвидация потерь и внедрение мероприятий по улучшению деятельности бизнеса.

Ведущими компаниями нефтегазовой отрасли внедрены системы управления операционной деятельностью - Operations Management System (OMS). Предпосылкой к решению стало событие 1989 года, когда на Аляске нефтяной танкер компании Exxon натолкнулся на риф, в результате чего произошла утечка более 150 тыс. тонн нефти, что повлекло экологический кризис и большие расходы компании на ликвидацию аварии. Руководство Еxхоn приняло серьезные меры по обеспечению промышленной безопасности и компания стала первым разработчиком системы управления операционной деятельностью (СУОД), в соответствии с которой обеспечивалась оптимизация операционной деятельности, безопасность и надежность активов. Командой разработчиков была составлена базовая документация, а также протокол оценки активов. Требования и стандарты каскадировались из корпоративного центра на нижестоящие уровни, и каждое предприятие, учитывая региональную специфику, использовало собственную систему, соответствующую глобальным стандартам. Ключевыми принципами системы являются ее систематический контроль производственной дисциплины, ежедневная практика OMS, создание единых групповых и локальных требований к системе. Немаловажным является фактор организационной культуры, влиявшим на развитие новой системы. Руководство компании демонстрировало приверженность OMS, и затем каждый сотрудник был вовлечен в программу. Частота смертельных случаев снижена в 13 раз, показатели в сфере безопасности и операционной деятельности улучшены, что способствовало применению данной технологии нефтегазовыми ведущими предприятиями, а также компаниями других отраслей промышленности [13].

В области телекоммуникаций и электронных систем также внедрена концепция управления производством корпорацией Motorola - шесть сигм. Данная система предполагает настройку регулярных бизнес-процессов на снижение всех потерь и дефектов посредством последовательного выполнения операций по устранению причин дефектов. Качество процесса оценивается качеством требуемых результатов, описываемых набором количественных показателей, которые обеспечивают данные о реальных изменениях в процессе. Этапы выполнения проекта шесть сигм включают определение задач, организацию работы; измерение дефектов; анализ дефектов; измерение причин; анализ причин; совершенствование; контроль. Несмотря на схожесть с другими инструментами, эффективность системы шести сигм обеспечивается за счёт сочетания её составляющих, гибкой организации последовательности их применения.

В российской судостроительной компании - Объединенной судостроительной корпорации, производственная система судостроения реализована посредством объединения двух подходов - бережливое производство и модернизация, что предполагает внедрение инновационных технологий в качественно организованной производственной среде. Это способствует более эффективному продвижению инновационных технологий и методов, так как излишние издержки могут снизить результат внедрения инноваций.

Если ранее судостроительная промышленность России была ориентирована в основном на постройку судов военного назначения, то сокращение данного типа заказов в 1990-е годы привело к снижению загрузки производственных мощностей судостроительных предприятий. В результате произошло изменение организационной структуры организаций, дезинтеграция судостроительной промышленности на отдельные предприятия. Новые условия повлекли сложности реализации деятельности, связанные с отсутствием готовности функционирования в условиях рыночных отношений. Исследуемый опыт показывает, в контексте неоиндустриализации необходима первоначально организация соответствующей среды для внедрения цифровых решений. Цифровая модель позволяет сопровождать решения всех этапов 
жизненного цикла судна, однако потери, дефекты, расходы неизбежны, если отсутствует качественно организованная производственная среда, соответственно эффект внедрения цифровых технологий будет значительно ниже. Отдельные цифровые решения позволяют выявить те действия, которые не добавляют ценности продукта и увеличивают себестоимость, например, лишняя транспортировка, избыточные запасы и др., а также неэффективные процессы во внешней среде.

Изучение научных трудов российских и зарубежных ученых, опыта ведущих предприятий мира судостроительной и других отраслей промышленности способствовало выявлению областей для улучшения деятельности предприятий судостроительной отрасли. Такими областями могут быть решения задач во внутренней среде предприятия - в области работы над потерями в бизнес-процессах, снижающих ценность продукта, и в области работы с внешней средой развитием промышленных коопераций.

В ходе исследования выявлено, что высокий потенциал развития может быть обеспечен за счет интеграции партнерских активов, развития межкооперационных сетей. Выявлено, что в условиях цифровой экономической среды важным является изменение структуры предприятий в сторону расширения сетевых форм организации. Межотраслевое, сетевое взаимодействие позволяет формировать новые комбинации ресурсов, соответственно, новые возможности и эффекты.

В настоящее время при взаимодействии с клиентами и партнерами отсутствии или низкое качество интеграции ограничивает возможности предприятий. В качестве вектора развития можно рассмотреть интеграционные проекты. Исследовательская и инновационная платформа, размещенная в Финляндии в университете Вааса является примером успешного решения по созданию технологической цифровой платформы для сетевого взаимодействия и кооперации в энергетической сфере. Также формирование межкооперационного сотрудничества стран ЕАЭС, России и Республики Беларусь может быть рассмотрено как перспективное направление [7].

В заключение отметим, успешность новых решений определяет не только внедрение цифровых технологий, но и контроль процессов, анализ эффективности, что невозможно без квалифицированных подготовленных кадров. Обеспечение конкурентоспособности предприятия возможно при разработке бизнес-модели, соответствующей реалиям. Анализ показал, что для наиболее успешного внедрения различных передовых технологий, как цифровые, необходима оптимизация бизнес-процессов на операционном уровне. Основополагающим является не сам процесс цифровизации предприятия, а эффективное устойчивое функционирование судостроительных предприятий в условиях неоиндустриализации.

\section{Библиографический список}

1. Национальный стандарт РФ ГОСТ Р 27.012-2019 «Надежность в технике. Анализ опасности и работоспособности (NAZOP)»

2. Морская доктрина Российской Федерации (утв. Президентом РФ 26.07.2015)

3. Распоряжение Правительства РФ № 2553-р от 28.10.2019 «Об утверждении Стратегии развития судостроительной промышленности на период до 2035 года»)

4. Распоряжение Правительства РФ от 30 августа 2019 г.№ 1930-р «О Стратегии развития морской деятельности РФ до 2030 года

5. Указ Президента РФ от 20.07.2017 № 327 «Об утверждении Основ государственной политики Российской Федерации в области военно-морской деятельности на период до 2030 года».

6. Карлик А.Е., Платонов В.В., Кречко С.А. Организационное обеспечение цифровой трансформации кооперационных сетей и внедрения киберсоциальных систем // Цифровая экономика: теория и практика. Научно-технические ведомости СПбГПУ. Экономические науки. 2019. Том 12, № 5 - С. 9-22

7. Лепеш Г. В. Формирование промышленной политики территорий России и Беларуси, ориентированной на расширение сетевого взаимодействия // Технико-технологические проблемы сервиса._- № 3 (53) 2020. - С. 3-12

8. Новая индустриализация России: стратегические приоритеты и возможности Урала / монография под ред. С. Д. Бодрунова, Я.П. Силина, В. Т. Рязанова, Е. Г. Анимицы; УрГЭУ - Екатеринбург: Изд-во УрГЭУ, 2018 - С. 34

9. Британское аналитическое агентство.- Электронный ресурс. - URL [https://www.clarksons.net/portal] (дата обращения 21.01.2021) 
10. Минпромторг России.- Электронный ресурс.- URL [https://minpromtorg.gov.ru/activities/industry/otrasli/ sudostroi/] (дата обращения 19.01.2021)

11. Морская политика России. Люди. События. Факты.- Электронный ресурс. - URL [http://marine.gov.ru/ upload/iblock/e1b/e1b919a893919f05b99d002d8213908f.pdf] (дата обращения 02.02.2021)

12. Методика NAZOP. - Электронный ресурс.- URL [https://protect-br.ru/blog/metodika-hazop-analiz-opasnostirabotosposobnosti/] (дата обращения 02.02.2021)

13. Operations Integrity Management System.- Электронный ресурс.- URL [https://corporate.exxonmobil.com/ Operations/Energy-technologies/Risk-management-and-safety/Operations-Integrity-Management-System] (дата обращения 02.02.2021)

14. Review of maritime transport // UNCTAD 2020.- Электронный ресурс.- URL [https://unctad.org/webflyer/ review-maritime-transport-2020] (дата обращения 21.01.2021)

15. www.infoline.spb.ru

16. Толкачев С.А. Условия и факторы неоиндустриального развития (fa.ru).

17. Губанов С. С. Новая страница 1 (есоnomist.com.ru).

18. Бодрунов С.Д. Формирование стратегии реиндустриализации России Монография. Санкт-Петербург, 2015.

19. Бодрунов С.Д. Реиндустриализация российской экономики: возможности и ограничения / Научные труды Вольного экономического общества России. 2014. 